\title{
NeuroRehab \\ News \\ Beneficios del ejercicio físico preoperatorio en la lesión de ligamento cruzado anterior
}

Patología y Ejercicio

\section{Infografía}

\section{Beneficios del Ejercicio Físico Preoperatorio en la Lesión del Ligamento Cruzado Anterior}

El ligamento cruzado anterior O LCA es la estructura estabilizadora primaria de la rodilla

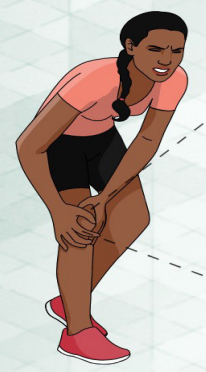

\section{Dolor} Inestabilidad Debilidad muscular

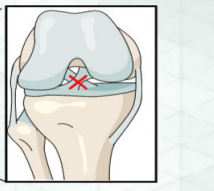

Limitación funcional Peor calidad de vida

Su lesión se asocia con la práctica deportiva y el tratamiento de elección es la cirugía en las personas que quieren reanudar un estilo de vida activo.

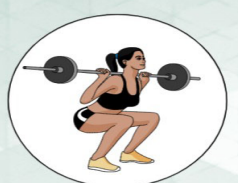

Rehabilitación preoperatoria o prehabilitación basada en ejercicio físico
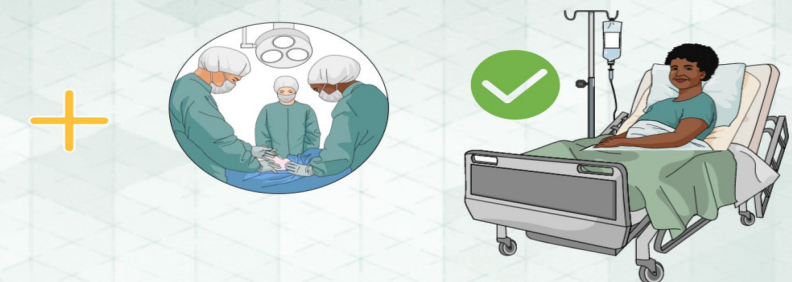

La prehabilitación prepara a la rodilla para la cirugía y maximiza los resultados de la rehabilitación postoperatoria.

\section{TRATAMIENTO}

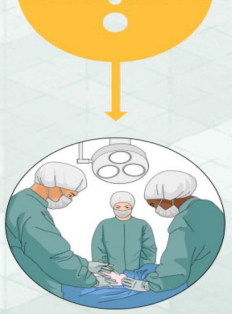

Cirugía de

reconstrucción del LCA
Previene:

- La debilidad muscular del cuádriceps

La limitación de la extensión de la rodilla

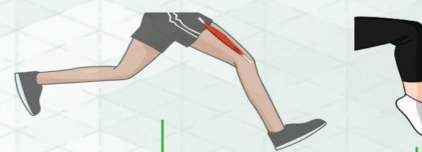

Acelera la recuperación postcirugía de:

- La fuerza muscular del cuádriceps

- El rango de movimiento de la rodilla
La articulación de la rodilla está formada por los huesos de la tibia, el fémur y la rótula, que están estabilizados por el ligamento colateral medial, el ligamento colateral lateral, el ligamento cruzado posterior y el ligamento cruzado anterior.

El ligamento cruzado anterior o LCA es la estructura estabilizadora primaria de la rodilla. El LCA limita el movimiento anterior excesivo de la tibia respecto al fémur y evita rangos extremos de rotación de la tibia.

La lesión del ligamento cruzado anterior es una de las lesiones de rodilla más comunes y se asocia con la práctica deportiva y el ejercicio físico. Así, se observa con mayor frecuencia en personas jóvenes y físicamente activas.

La mayoría de las lesiones del LCA son resultado de un mecanismo sin contacto asociado con el aterrizaje tras un salto, un cambio de dirección o una desaceleración repentina de la extremidad inferior con la rodilla en extensión total o cerca de ella, como ocurre en el fútbol, el baloncesto, el esquí, el balonmano y el voleibol. El resto de lesiones son resultado de un mecanismo con contacto. La lesión del LCA está asociada con diversos grados de dolor, sensación de fallo o inestabilidad de la rodilla, debilidad muscular, limitación funcional y peor calidad de vida.

Los objetivos del tratamiento tras la lesión del LCA son restaurar la función de la rodilla a corto plazo y prevenir la aparición de alteraciones degenerativas en dicha articulación a largo plazo. La edad del paciente, su nivel de actividad, sus expectativas funcionales, laborales y deportivas, el grado de inestabilidad de la rodilla y la presencia de otras lesiones en dicha articulación juegan un papel importante en la decisión del tratamiento apropiado después de la lesión del LCA. La cirugía de reconstrucción del LCA es el tratamiento de elección para los pacientes con el deseo de reanudar un estilo de vida activo.

Si bien la cirugía corrige el defecto en la estructura del ligamento, muchos pacientes experimentan una deficiencia postoperatoria en la fuerza muscular, especialmente en el músculo cuádriceps, cuya función principal es la extensión de la pierna, y en la función de la rodilla, lo que limita su capacidad para retomar las diferentes actividades de la vida diaria.

Un déficit preoperatorio en la extensión de la rodilla es un factor de riesgo importante para presentar un déficit de extensión después de la cirugía de reconstrucción. Por otro lado, un déficit en la fuerza muscular preoperatoria del cuádriceps predice una fuerza postoperatoria del cuádriceps más baja y una peor función de la extremidad inferior. Así, un rango de movimiento completo en la extensión de la rodilla y una fuerza normal del cuádriceps antes de 
la cirugía de reconstrucción del LCA están asociados con mejores resultados postoperatorios.

Estos hallazgos resaltan la importancia de implementar una rehabilitación preoperatoria o prehabilitación basada en ejercicio físico para preparar a la rodilla para la cirugía de reconstrucción y maximizar los resultados de la rehabilitación postoperatoria, facilitando así la recuperación de los pacientes.

La duración promedio de la rehabilitación preoperatoria es de 14 semanas, con una frecuencia de sesiones que oscila entre 2 y 4 sesiones por semana. Hay evidencia científica que sugiere que el ejercicio físico preoperatorio puede producir varios efectos positivos después de la cirugía de reconstrucción. La prehabilitación no solo puede prevenir la debilidad del músculo cuádriceps y la limitación de la extensión de la rodilla, sino que también puede acelerar la recuperación de la fuerza muscular del cuádriceps y del rango de movimiento de la rodilla tras la cirugía.

\section{Sobre este artículo:}

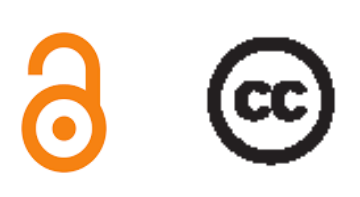

\section{Fuente /s:}

-Alshewaier, S., Yeowell, G., \& Fatoye, F. (2017). The effectiveness of pre-operative exercise physiotherapy rehabilitation on the outcomes of treatment following anterior cruciate ligament injury: A systematic review. Clinical Rehabilitation, 31;(1):34-44. https://doi.org/10.1177/0269215516628617

-Kim, D. K., Hwang, J. H., \& Park, W. H. (2015). Effects of 4 weeks preoperative exercise on knee extensor strength after anterior cruciate ligament reconstruction. Journal of Physical Therapy Science, 27;(9):2693-2696. https:// doi.org/10.1589/jpts.27.2693

-Siegel, L., Vandenakker-Albanese, C., \& Siegel, D. (2012). Anterior cruciate ligament injuries: Anatomy, physiology, biomechanics, and management. Clinical Journal of Sport Medicine, 22;(4):349-355. https://doi.org/10.1097/ JSM.0b013e3182580cd0

Fuente de la Imagen: imagen de NeuroRehabnews.com con fines unicamente ilustrativos.

Para citar este artículo: Madroñero-Miguel B. Beneficios del ejercicio físico preoperatorio en la lesión de ligamento cruzado anterior. NeuroRehab News 2020 mar; 4(1):e0071.

Beatriz Madroñero Miguel

Edición: Ferran Cuenca Martínez y Roy La Touche 